Case report

\title{
Indoxacarb - a rare cause of poisoning
}

\author{
Rathnayaka R M M K N ${ }^{1}$, Wijekoon C N², Sugathapala A G $\mathrm{H}^{3}$, Ranathunga P E A N
}

Journal of the Ceylon College of Physicians, 2016, 47, 46-47

Key words: indoxacarb, methaemoglobin, methaemoglobinemia, methylene blue

\section{Introduction}

Indoxacarb is a non-organophosphorus oxadiazine insecticide that is considered a safe substitute for organophosphate insecticides. ${ }^{1}$ It acts by blocking sodium channels in the nervous system of insects. However, there is limited data concerning human toxicity. A literature survey revealed only eight case reports and one case series of ten patients worldwide and there were none from Sri Lanka.

\section{Case report}

A 32-year-old male tea cultivator was transferred to Provincial General Hospital, Ratnapura from a local hospital with a history of deliberate ingestion of 'Avaunt' (Indoxacarb 150g/L EC). He has ingested about $50 \mathrm{ml}$ of indoxacarb around $10 \mathrm{pm}$ the previous day and had received gastric lavage and activated charcoal at the local hospital. He had no significant past medical problems. On admission he was restless. Glasgow Coma Score (GCS) was 15/15. Pupils were dilated but were equally reacting to light. He was cyanosed. $\mathrm{His}$ respiratory rate was $30 / \mathrm{min}$ and $\mathrm{SpO}_{2}$ was $88 \%$ on room air. Crepitations were found in both lung fields. His blood pressure was $120 / 80 \mathrm{mmHg}$ and pulse rate was $110 / \mathrm{min}$. While sampling blood for routine investigations it was noted that the blood color was brownish. Possibility of methaemoglobinemia was considered. As resources were not available to measure blood methaemoglobin (MetHb) level it was assessed

\footnotetext{
${ }^{1}$ Trainee in Medical Toxicology, Medical OfficerIntensive Care Unit, Anaesthesia, Provincial General Hospital, Ratnapura, Sri Lanka.

${ }^{2}$ Senior Lecturer, Department of Pharmacology, Faculty of Medicine, University of Kelaniya, Sri Lanka.

${ }^{3}$ Consultant Physician, Provincial General Hospital, Ratnapura, Sri Lanka.

${ }^{4}$ Medical Officer, Emergency Treatment Unit, Provincial General Hospital, Ratnapura, Sri Lanka.
}

Corresponding author: R M M K N R, E-mail: namalrath10@yahoo.com at bedside using the standard colour chart. ${ }^{2}$ As immediate management oxygen $10 \mathrm{~L} / \mathrm{min}$ was given via face mask, a normal saline infusion was started and vital functions were monitored. As MetHb level was $50 \%$ according to the colour chart a bolus dose of methylene blue $50 \mathrm{mg}(1 \mathrm{mg} / \mathrm{kg})$ was given immediately. Subsequently the patient was transferred to Intensive Care Unit (ICU) for further management.

On admission to ICU, he was still cyanosed and irritable. Arterial blood gas (ABG) analysis with $60 \% \mathrm{O}_{2}$ showed pH 7.488, pCO 27.5mmHg, pO $379.7 \mathrm{mmHg}^{2}$, $\mathrm{HCO}_{3} 21.1 \mathrm{mmol} / \mathrm{L}$ and base excess $2.5 \mathrm{mmol} / \mathrm{L}$. Chest $\mathrm{x}$-ray was normal. After reassessing MetHb level he was treated with methylene blue $50 \mathrm{mg}(1 \mathrm{mg} / \mathrm{kg})$ as a bolus followed by another $50 \mathrm{mg}$ in $100 \mathrm{ml}$ of normal saline infused over one hour. This regimen was repeated 8 hourly while monitoring MetHb level using the colour chart. He was also given oral ascorbic acid (vitamin C) $500 \mathrm{mg}$. After 24 hours MetHb level reduced to 10\%, cyanosis disappeared and he was transferred back to the ward.

On admission random blood glucose, serum creatinine, serum electrolytes, full blood count and 12lead ECG were normal. Liver profile was also normal except a mild elevation of aspartate transaminase $(74 U / L)$. Blood picture done on the 4th day showed compensated mild haemolysis. His renal function was not affected. He recovered over a week. After assessment by the psychiatrist he was started on imipramine and discharged home with follow up plans.

\section{Discussion}

The reported complications of indoxacarb poisoning include methaemoglobinemia, acute kidney injury and rhabdommyolysis. . $^{3,4}$ The main problem observed in this patient was methaemoglobinemia. $\mathrm{MetHb}$ is generated by oxidation of ferrous $(\mathrm{Fe}+2)$ in haem iron to the ferric $(\mathrm{Fe}+3)$ state which causes characteristic bluish colour resembling cyanosis. MetHb has a high affinity to oxygen resulting in impaired delivery of oxygen to tissues. In a patient who appears cyanotic with low $\mathrm{SpO}_{2}$ on pulse oximetry and normal $\mathrm{PaO}_{2}$ on $A B G$, methaemoglobinaemia should be suspected. ${ }^{5}$ This patient had cyanosis and low $\mathrm{SpO}_{2}$ on pulse oximetry. ABG could not be performed on 
admission but ABG at ICU showed extremely high $\mathrm{PaO}_{2}$ while patient was clinically cyanosed. Methemoglobinaemia can also be suspected if the fresh drawn blood has characteristic chocolate brown appearance. ${ }^{5}$ Normally blood MetHb level is less than 1\%. Cyanosis usually manifests at a level between $10-20 \%$. Levels $>60 \%$ are considered to be lethal. Antidote is indicated when MetHb level is $>20 \%$. $^{5}$

Unavailability of resources to measure blood MetHb level poses a challenge in managing such patients in developing countries like Sri Lanka. The alternative is assessing the MetHb level using the standard colour charts developed by Shihana F. et al. ${ }^{2}$ This patient received the antidote as the MetHb level was estimated to be $50 \%$. Intravenous methylene blue is the antidote for methaemoglobinemia. The recommended dose is $1-2 \mathrm{mg} / \mathrm{kg}$ which could be repeated depending on the patient's response and MetHb level. The recommended maximum daily dose is $7 \mathrm{mg} / \mathrm{kg} /$ day. When the dose is too high it can worsen methaemoglobinemia paradoxically. ${ }^{5}$ The main side effect of methylene blue is haemolytic anaemia and a mild haemolysis was observed in this patient on the 4th day.

This is the first reported case of indoxacarb poisoning in Sri Lanka. He was successfully managed in spite of resource limitations. This case also illustrates the general approach to the management of methaemoglobinemia.

\section{References}

1. McKinley N, Kijima S, Cook G, Sherrod D. Avaunt (indoxacarb): A new mode of action insecticide for control of several key orchard pests. Proceedings of the 76th Annual Western Orchard Pest and Disease Management Conference 9-11 January 2002 published by Washington State Univ., Pullman, Washington. http://entomology. tfrec.wsu.edu/wopdmc/2002PDFs/Rep02\%20 Chemical \%20McKinley.pdf (cited 1st December 2014)

2. Shihana F, Dissanayake D., Buckley NA, Dawson AH. A Simple Quantitative Bedside Test to Determine Methemoglobin. Annals of Emergency Medicine 2010; 55 (2-13): 184-9.

3. Prasanna L, Rao SM, Singh V, et al.. Indoxacarb poisoning: An unusual presentation as methemoglobinemia. Indian Journal of Critical Care Medicine 2008; 12(4): 198-200.

4. Kyubok Jin. Rhabdomyolysis, methaemoglobinemia and acute kidney injury after indoxacarb poisoning. Clinical Toxicology 2012; 50(3): 227.

5. Wikitox.http://curriculum.toxicology.wikispaces.net/ Methemoglobin (cited 1st December 2014) 